\title{
Pentazocine Abuse in Two Siblings with Sickle Cell Anaemia
}

\author{
Samuel Kolade Ernest ${ }^{1}$, Israel Kayode Kolawole ${ }^{2}$, Benedict Oluwasesan Olorunsola1, \\ Oluwaseun Taofik Ogunkunle1, Oluwatosin Adeniyi Ojuola1, Tryphena Jadesola Oyedepo', \\ Segun Opeyemi Jenyo ${ }^{1}$
}

\author{
${ }^{1}$ Department of Paediatrics, University of Ilorin Teaching Hospital, Ilorin, Nigeria \\ ${ }^{2}$ Department Anaesthesia and Palliative Care, University of Ilorin Teaching Hospital, Ilorin, Nigeria \\ Email: skernest@unilorin.edu.ng
}

How to cite this paper: Ernest, S.K., Kolawole, I.K., Olorunsola, B.O., Ogunkunle, O.T., Ojuola, O.A., Oyedepo, T.J. and Jenyo, S.O. (2019) Pentazocine Abuse in Two Siblings with Sickle Cell Anaemia. Open Journal of Pediatrics, 9, 148-153. https://doi.org/10.4236/ojped.2019.92016

Received: March 29, 2019

Accepted: May 28, 2019

Published: May 31, 2019

Copyright $\odot 2019$ by author(s) and Scientific Research Publishing Inc. This work is licensed under the Creative Commons Attribution International License (CC BY 4.0).

http://creativecommons.org/licenses/by/4.0/

\begin{abstract}
Vaso-occlusive crisis is a common clinical manifestation in children with sickle cell anaemia, frequently warranting in-patient management with intravenous fluids, analgesics and occasionally anti-malaria and antibiotics. Pain is the principal symptom of vaso-occlusive crisis and it can affect any part of the body. Pentazocine is a well-known opioid analgesic, commonly used in the treatment of painful crisis in children affected by sickle cell anaemia. It was discovered in the 1950s and was initially thought to be addiction-proof, but this has been disproved over the years by reports of pentazocine dependence/addiction especially in patients living with chronic pain. There have been some case reports of pentazocine abuse/dependence among sickle cell disease patients in the literature, most of which are from Nigeria but none involved joint addiction by siblings. We therefore, report the case of two siblings, known sickle cell anaemia (HbSS) patients, referred to our emergency paediatric unit with history of recurrent painful crisis over a 10 -month period leading to abuse of pentazocine. They were jointly managed successfully by the paediatric hematology and the pain and palliative units of the University of Ilorin Teaching Hospital and helped to overcome their abuse and addiction.
\end{abstract}

\section{Keywords}

Pentazocine, Abuse, Siblings, Sickle Cell Anaemia

\section{Introductory Backgrounds}

Sickle cell disease refers to a spectrum of inherited red cell disorder in which an affected individual has 2 abnormal haemoglobin one of which is the $\mathrm{S}$ haemog- 
lobin. The most severe form of this disorder is sickle cell anaemia in which the affected individual is homozygous for the abnormal S haemoglobin. About 2\% $3 \%$ of Nigerian newborns are homozygous for the $\mathrm{S}$ haemoglobin and incidence in the general Nigerian population is 1:300. Affected children usually have recurrent episodes of acute illnesses typically referred to as "crises". Two major types of crises have been well described and studied. These include vaso-occlusive crisis and Anaemic crisis. Anaemic crisis has four types (Sequestration crisis, Aplastic crisis, Megaloblastic crisis and Hemolytic crisis). However, mixed crisis do occur. Vaso-occlusive crisis is the most common and can affect any part of the body. Patients typically present with pain which could range from mild to severe. Depending on the severity of the pain, mild forms can be successfully managed at home with oral analgesics and liberal oral fluid intake; severe cases however usually require inpatient management with IV analgesics, antimicrobials and fluid. Affected children can have up to an average of 6 episodes of painful crisis requiring hospital admission in a year; some have more while some have less. As such, sickle cell disease patients can be said to suffer from some form of chronic or recurrent pain frequently requiring use of either oral or parenteral analgesics.

We have evidence that the development of pentazocine started in the 1950s. What prompted that was the need to get an analgesic with relative effectiveness of morphine without the risk of addiction like morphine [1]. Early report on pentazocine indicated that it might meet such aspiration [2]. In the 1965 session of the World Health Organization's Expert Committee on Dependence-producing Drugs considered that there was little likelihood of abuse of pentazocine, that pentazocine presents no significant risk to public health and that there was no need at that time for narcotic control of pentazocine nationally or internationally [3].

Pentazocine, an opioid analgesic, was initially thought to have a better safety profile than morphine with regards to dependence but this was quickly disproved with myriads of reports of dependence that followed its discovery [4]. Pentazocine has a more rapid onset of analgesic action than morphine but shorter duration. Dose-for-dose, $40 \mathrm{mg}$ of pentazocine will give similar analgesic effect as $10 \mathrm{mg}$ of morphine [5].

It is frequently abused by patients suffering from chronic pain and this has been attributed to factors such as its earlier onset of action (15 minutes), ready availability and the dysphoric effect it gives.

It is also commonly prescribed by clinicians in Nigeria for the management of painful crisis in patients with sickle cell disease and there have been several case reports of pentazocine abuse/dependence in patients who have sickle cell disease [6] [7] [8]. Sagir and co-workers found the prevalence rate of opiate dependence to be $17.8 \%$ among sickle cell disease patients seen at the University of Maiduguri Teaching Hospital, Nigeria [9]. The present cases were reported to raise high index of suspicion among physicians and help others who may be at risk of self-medication and drug abuse. 


\section{Summary of Cases}

Two female siblings aged 14 and 17 years were referred to our emergency unit on account of recurrent bone pains in the past 10 months. They were both sickle cell anaemia patients, diagnosed at age six months and had been on follow up care at the referring hospital. The usual frequency of painful crisis was about 2 3 times in a year for both of them but in the past 10 months before referral, frequency has increased to an average of 3 times per week. Pain usually involved the limbs and the back, was usually not associated with fever or swelling of any of the involved parts but was severe enough to keep them from their daily activity of schooling and normal house chores.

At the onset of frequent painful crisis, they were admitted several times at a General Hospital where dihydrocodeine, ibuprofen, pentazocine, antimalaria, several antibiotics and IV fluids were used to manage the pain. Pain however became more frequent following discharge despite use of several analgesics and frequent hospital visits. The mother, a 34 years old businesswoman, also noticed that intramuscular pentazocine appeared to be the only analgesic potent enough to relieve pain and children demanded for it regularly. This prompted their mother, who was the major caregiver, to seek help from a nurse who lived in the neighborhood to teach her how to administer intramuscular pentazocine at home. The drug was subsequently procured regularly with the help of the nurse and mother gave each of them $15 \mathrm{mg}, 6$ to 8 hourly or 3 to 4 times daily, usually on the thigh. Despite regular use of pentazocine (up to 5 days in a week), painful crisis appeared to increase in frequency and severity, with the children requesting for more doses of pentazocine. Mother administered these frequent doses of pentazocine for more than three weeks. In spite of this, patients were making demands for more doses and that informed their mother's decision to return to the primary health care providers where they were referred to our Centre, University of Ilorin Teaching Hospital.

At presentation to our unit, patients were in severe painful distress, crying and asking for pain relief, specifically pentazocine. Pain assessment was 8 in 10. The elder sister had an injection abscess on the right thigh, otherwise, examination findings were essentially normal. They were subsequently assessed to be having vaso-occlusive crisis and were initially commenced on IV fluids, dihydrocodeine and pentazocine each at $30 \mathrm{mg} 8$ hourly. All initial laboratory investigations done were within normal limits. We however, had no facility for testing opioids and other drugs in either blood or urine.

In the first 48 hours of admission, they were observed to be having almost continuous pain despite adequate fluids and regular analgesia, pain was severe enough to make them cry and prevented them from sleeping and was only relieved with PRN doses of pentazocine, such that they had an average of 6 doses of $30 \mathrm{mg}$ pentazocine daily and still requested for more pain relief, specifically asking for pentazocine. This prompted the decision to give them sterile water as a form of placebo treatment. Pain appeared to subside following administration 
of the placebo. At this point an assessment of Pentazocine Abuse was considered and the Behavioral Scientists together with the Pain and Palliative unit were invited. However, Behavioral Scientist could not review on account of an ongoing industrial action.

They were seen by the Pain and Palliative unit of the Hospital on the third day of admission, who discontinued pentazocine and commenced them on morphine 6 hourly, they initially needed about 3 - 4 doses of morphine every day to achieve pain relief, this was gradually tapered off until they became pain free. It was noted that while on morphine, they frequently requested for pentazocine and would sometimes cry for it. During the course of admission, they developed fever and had IV ciprofloxacin following result of a repeat Full blood count that was suggestive of sepsis.

Before discharge, following resolution of the initial symptoms, a counseling session involving the managing team (the unit Consultant, residents and interns) and the pain and palliative unit representative, was held, where the two girls and their mother were made aware of the hazards of indiscriminate drug use and its attendant untoward effects, especially opioids such as pentazocine. They asked questions freely, all of which were duly answered. A feedback was also written to the primary healthcare providers, detailing the diagnosis made and how they were managed. Also both patients and parents were positive about the outcome and consent to sharing the cases to raising high index of suspicion and helping others who may be at risk of self-medication and drug abuse.

They were seen after a month at the sickle cell clinic, one of them, the younger one, had an episode of painful crisis after discharge which was managed at home with oral ibuprofen, liberal fluid intake and adequate rest and which resolved after 2 days. They are still being followed up at the clinic.

\section{Discussion}

Pentazocine abuse among sickle cell patients has been documented by several authors and most of these reports come from developing countries like ours where there is no firm legislation against access and use of controlled substances [10]. This could also be attributed to the higher prevalence of sickle cell disease among people of African ancestry. Moreover most of the reported victims of pentazocine abuse/dependence were adolescents and young adults suffering from recurrent or chronic pain as seen in this report, although a slight difference is the role played by the principal caregiver who happens to be the mother of the children. Again it is evident that ignorance was a major factor in these cases as the mother and the children readily owned up to the indiscriminate use of the drug when questioned about it with no attempts to withhold information. This points to the fact that they were unaware of the risk pentazocine abuse posed to them and did not see their indiscriminate use of the drug as harmful.

Furthermore we noted the role the healthcare worker played in the acquisition of these drugs with ease, as with other documented cases, most of the affected individuals had contact with an healthcare worker or a facility where they could 
procure the drugs without difficulty and some were even taught how to self administer the drugs as was the case in this report [4].

Although we could not demonstrate classical signs and symptoms of pentazocine dependence in these cases which is usually evidenced by withdrawal symptoms of restlessness, tremor, runny nose, fever, vomiting, abdominal cramps, nausea etc., it was however obvious that the children were beginning to need higher doses to achieve pain control.

In contrast to what is usually the case, there was as yet no documented adverse effect of pentazocine abuse as it did not appear to have psychosocial effects on the behavior of these girls. They were not reported to be engaging in antisocial activities in order to procure the medication, this was probably because the drug abuse was moderated by the mother and she was quickly referred when it was getting out of hand. The older patient had some academic setback as she was still in Junior Secondary School (JSS) 3 at the age of 17 years which should have been attained at 13 years of age. This may however, attributable to school absenteeism due to painful crises and previous hospital admissions before Pentazocine abuse.

Again, these adolescents did not benefit from a psychiatric evaluation on account of an ongoing industrial strike, they were however jointly managed by the paediatric hematology and pain and palliative unit of the hospital.

\section{Conclusions and Recommendations}

We concluded that painful crises and maternal ignorance initiated this abuse but the healthcare worker aided the procurement of the abused medication in these siblings. It is therefore recommended that:

1) There should be more public awareness about drug abuse and its attendant consequence especially for drugs that also serve therapeutic purposes.

2) Laws guiding access and use of controlled drugs should be strengthened and enforced to reduce access to drugs.

3) Health workers need to be trained and retrained on use of analgesics for acute or chronic pain management.

4) Management protocol of sickle cell painful crisis should be harmonized and communicated to the primary health care facilities and the private hospitals where these patients usually present to first. But drugs with high addictive profile should not be made easily available at primary care centers.

5) Patients with sickle cell disease having recurrent pain should be considered at risk of analgesic abuse and should be identified promptly for early interventions.

6) More studies are needed to identify the prevalence of opioid dependence among patients with sickle cell disease and more emphasis placed on care of those suffering from this problem; this could include creation of support groups, rehabilitative facilities amongst others.

\section{Conflicts of Interest}

The authors declare no conflicts of interest regarding the publication of this paper. 


\section{References}

[1] Lasagna, L. and Beecher, H.K. (1954) The Analgesic Effectiveness of Nalorphine and Nalorphine-Morphine Combinations in Man. Journal of Pharmacology and Experimental Therapeutics, 112, 356-363.

[2] Keats, A.S. and Telford, J. (1956) Nalorphine, A Potent Analgesic in Man. Journal of Pharmacology and Experimental Therapeutics, 117, 190-196.

[3] World Health Organization (1966) Expert Committee on Dependence-Producing drugs. Technical Report Series No. 343. WHO, Geneva, 6.

[4] Inciardi, J.A. and Chambers, C.D. (1971) Patterns of Pentazocine Abuse and Addiction. New York State Journal of Medicine, 71, 1727-1733.

[5] Bellville, J.W. (1967) Pentazocine-A Nonaddicting Analgesic. Annals of Internal Medicine, 67, 1114-1115. https://doi.org/10.7326/0003-4819-67-5-1114

[6] Yusha, A., Garba, B.I. and Haliru, D.G. (2016) Intravenous Pentazocine Dependence in a Young Sickle Cell Anemia Patient : A Case Report. Case Reports International, 5, 1-4.

[7] Awusi, V.O. and Lawani, E.B. (2011) Dependence Syndrome in a Male Nigerian Adult with Sickle Cell Anaemia: A Case Report. Biosciences, Biotechnology Research Asia, 8, 623-626. https://doi.org/10.13005/bbra/911

[8] Onyencho, V.C., Pindar, S.K., Mshelia, A.A., et al. (2016) Case Report: A Report of Personality Disposition and Pentazocine Abuse in Sickle Cell Anemia Patients: A Report of Two Cases. Pyrex Journal of Medicine and Medical Sciences, 3, 1-4.

[9] Ahmed, S.G. and Ibrahim, U.A. (2001) The Prevalence of Therapeutic Opiate Dependence among Patients with Sickle Cell Disease in Maiduguri, North-East Nigeria. Nigerian Journal of Pharmacy, 32, 56-59.

[10] Mudrick, C., Isaacs, J., Frankenhoff, J. (2011) Case Report: Injectable Pentazocine Abuse Leading to Necrotizing Soft Tissue Infection and Florid Osteomyelitis. Hand, 6, 457-459. https://doi.org/10.1007/s11552-011-9359-Z 